\title{
Acoustic emission characteristics of instability process of a rock plate under concentrated loading
}

\author{
S.R. Wang \\ Opening Project of Key Laboratory of Deep Mine Construction, Henan Polytechnic University, Jiaozuo 454003, P.R China \\ w_sr88@163.com \\ C.Y. Li \\ School of Civil Engineering, Henan Polytechnic University, Jiaozuo 454003, P.R China
}

Z.S. Zou, X.L. Liu

Opening Project of Key Laboratory of Deep Mine Construction, Henan Polytechnic University, Jiaozuo 454003, P.R China

\begin{abstract}
It can facilitate the understanding of the mechanical properties and failure laws of rocks to research on the rock failure mechanism and evolution characteristics of Acoustic Emission (AE). Under the concentrated loading condition, the fracture and instability test of a rock plate was conducted by using the rock Mechanics Testing System (MTS), meanwhile, these AE events were recorded through the AE recording system. Based on the laboratory test, the numerical simulation was completed by using FLAC ${ }^{3 \mathrm{D}}$ technique under the criterion that the rupture of a cell or several adjacent cells was regarded as an AE event. The results show that the process of the fracture and instability of the rock plate can be divided into four stages, such as the stress adjusting stage, the brittle fracture stage, the rock-arch bearing load stage and the rock-arch instability stage. And the acoustic emissions display the different characteristics in each one of the four stages. The temporal and spatial distribution characteristics of the AE events with large magnitudes are very similar to those of the natural earthquakes.
\end{abstract}

KEYWORDS. Rock mechanics; Rock plate; Acoustic emission; Numerical simulation; Instability.

\section{INTRODUCTION}

S ince rock failure is always accompanied by Acoustic Emission (AE) phenomenon, it can facilitate the understanding of the mechanical properties and failure laws of rocks to research on the rock failure mechanism and evolution characteristics of acoustic emission.

Currently, the study methods of AE mainly contain the means of laboratory test or numerical simulation or both of them. In the experimental research field, both domestic and foreign scholars have conducted plenty of studies. For example, S.L. $\mathrm{Li}$, et al. investigated the rock mechanics and $\mathrm{AE}$ characteristics in the whole failure process for rock samples and pointed out the test results could be used to explain the AE phenomenon in an engineering project [1]. X.M. Fu compared the similarities and differences of these AE performances for different rocks in the uniaxial compression tests [2]. Based on the locations of AE events, X.D. Zhao, et al. found that the AE distribution could reflect the shape and development of 
the cracks in rocks, which is meaningful to study the deformation and failure laws of rocks [3]. J.P. Liu, et al. observed the changes of $\mathrm{AE}$ number in a process of loading test, found that the accelerating release of energy was meaningful to predict the instability or failure of the rock mass [4]. Y.B. Zhang inferred the AE magnitude by the ratio of the whole released energy and AE number in a particular time, found that the higher the ratio, the less AE events had produced the energy [5]. L.C. Jia, et al. monitored the process of the uniaxial compression test for limestone by acoustic emission techniques, and elaborated the crack development law in the rock sample after scanning the destroyed samples by a Computerized Tomography (CT) machine [6]. B.X. Huang, et al. analyzed the stress-strain curves and AE characteristics for coal-bearing rock samples under different stress paths [7]. K. Zhao, et al. conducted the research on AE characteristics of phyllite specimens under uniaxial compression tests [8]. M. Karakus, et al. analyzed the AE signal in the rock drilling process, which would provide the guidance to improve the drilling effect [9]. E. Aker, et al. analyzed the differences of AE between the shear failure and tensile failure in the triaxial compression tests of sandstone and predicted the failure mechanism using the proportion of the isotropic and anisotropic moment tensors [10]. L.P. Frash, et al. conducted the granite tests using $\mathrm{AE}$ technique and simulated the evolution of the crack in the geothermal development, providing useful information for the engineering application [11]. The numerical simulation can show some information that the laboratory tests cannot provide. For example, some scholars simulated AE by using Particle Flow Code (PFC) and Rock Failure Process Analysis system (RFPA), which provided a great help to understand AE phenomenon [12, 13]. Additionally, based on the correspondence between AE and cell rupture in FLAC/FLAC ${ }^{3 \mathrm{D}}$ code, X.B. Wang and T.C. Han et al. $[14,15]$ respectively simulated the AE in both laboratory and engineering scales, and they all obtained the good results. And other related works [16-18].

Based on the laboratory test, a further research following the above mentioned results will be conducted by using FLAC $3 \mathrm{D}$ technique under the criterion that the rupture of a cell or several adjacent cells was regarded as an AE event. We will analyze the temporal and spatial distribution characteristics of the $\mathrm{AE}$ events with large magnitudes and discuss the relationships between $\mathrm{AE}$ and natural earthquakes.

\section{MATERIALS AND METHODS}

\section{Samples of Rock Plates}

7 he rock plate samples in the tests were Hawkesbury sandstones, which were obtained from Gosford Quarry in Sydney, Australia. The quartz sandstones were formed in marine sedimentary basin of the Mid-Triassic and located on the top of the coal-bearing strata, which contained a small quantity of feldspars, siderite and clay minerals. According to the definition of the thick plate in elastic mechanics, the specimen sizes of the thick plate were designed as $190 \mathrm{~mm} \times 75 \mathrm{~mm} \times 24 \mathrm{~mm}$ (length, width and thickness).

\section{Equipment and AE Acquisition System}

The MTS-851 rock mechanics testing machine was selected as the loading equipment, and the load was controlled by vertical displacement and the loading rate was set $1 \times 10^{-2} \mathrm{~mm} / \mathrm{s}$. The vertical force and displacement in the process of the test were automatically recorded in real time by the data acquisition system.

As shown in Fig. 1, the concentrated loading tests were designed to mainly consist of three parts. The top was a pointloading for the concentrated loading. The middle was a loading framework which included four bolts with nuts connecting the steel plates on both sides, and the lateral pressure cell was placed between the deformable steel plate and the thick steel plate so as to monitor the horizontal force. The capacity of the lateral pressure cell LPX was $1000 \mathrm{~kg}$. The bottom was a rectangle steel foundation, and the rotatable hinge support was set on the both sides of the loading framework to maintain the connections with the steel plates.

To monitor the cracks initiating and identify the failure location of the rock plate, the USB AE Nodes were used in the test. The USB AE Node is a single channel AE digital signal processor with full AE hit and real time features. In the test there were four USB AE nodes connected to a USB hub for multi-channel operation (Fig. 2). All these AE Nodes were made in MISTRAS Group Inc. USA.

\section{Numerical Simulation Scheme}

$\mathrm{AE}$ is due to the internal micro fracture by tension, shearing and compression stress in the rock plate, and this process is accompanied by the release of elastic waves. The rupture of a cell in FLAC3D is also accompanied by the release of elastic energy, so it can be used to simulate an $\mathrm{AE}$ event [15]. In fact, if several adjacent cells rupture in the rock plate in a calculating cycle (step), it should also be regarded as an AE event, which advantage is that we can record the number of 
the ruptured cells reflecting the magnitude of the energy in an AE event. Then we can analyze the evolution characteristics of temporal and spatial of AE events, which may facilitate the understanding of the mechanical properties and failure laws of rocks.

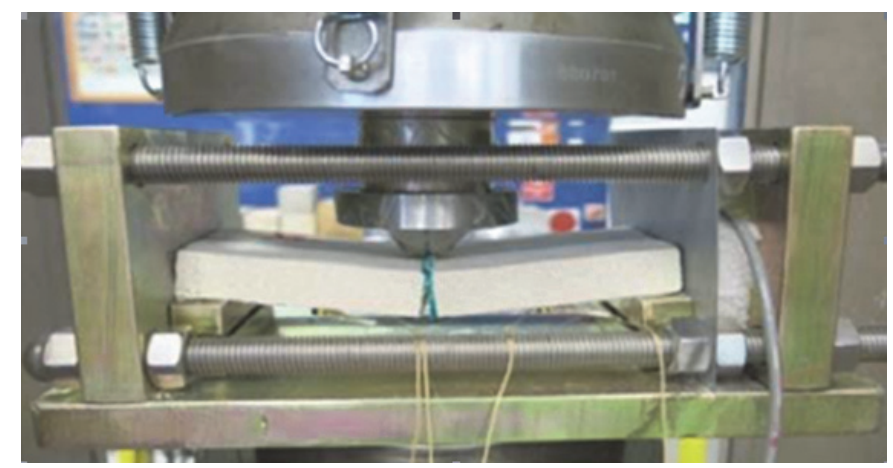

Figure 1: The concentrated loading test for rock plate.

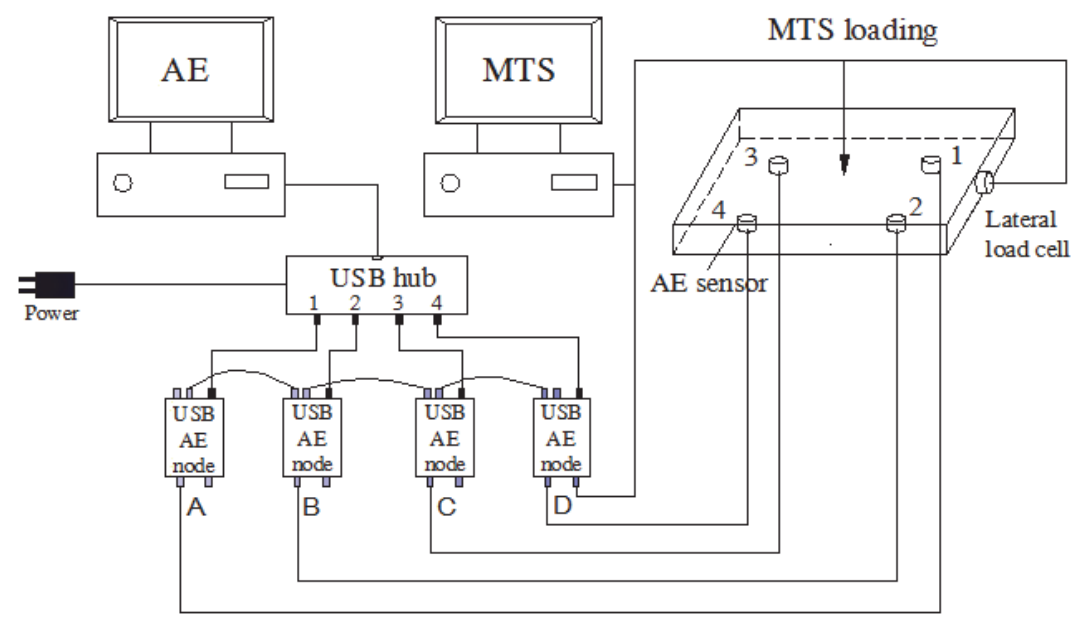

Figure 2: MTS and AE monitoring system diagram.

We assumed that if an $\mathrm{AE}$ event during the simulation test corresponded to only one ruptured cell, the center of this cell was defined the AE event location, or if an AE event corresponded to several adjacent cells, the center of the cells near the nuclear of the block was defined the $\mathrm{AE}$ event location. Then a recording function was written by FISH language embedded in FLAC $3 \mathrm{D}$ code to record the information of AE events such as the number of ruptured cells, the locations and the magnitudes of the AE events. The realization process of this function was shown in Fig. 3. The state of each cell was defined as ruptured or not and all of the cells were judged during each calculating step. In addition, the cells were regarded as 'adjacent cells' if the distance between two cells was less than $3.16 \mathrm{~mm}$. Finally, the large magnitude AE events, namely the events corresponding to two or more ruptured cells were abstracted for being analyzed. So these AE characteristics in the test were analyzed through observing the temporal and spatial distribution of the large magnitude AE events.

\section{Computational Model and Parameters}

The computational model was the same size of the sandstone sample as shown in Fig. 4, which combined 68992 cells totally and each cell was a cube element measuring $1.7 \mathrm{~mm}$ on each side. To simulate the defects in the rock plate, about 14000 defective cells were generated by a FISH function. These defects were randomly distributed in the main cells to form a Block Group. In addition, a new Block Group containing these weak cells was defined to reflect the tension strength decreasing in the middle of the rock plate bottom after the initial crack being developed in the test. Therefore, all the cells belonged to three groups: the main cells, the defective cells, and the weak cells (Fig. 4).

The Mohr-Coulomb strength criterion was applied and the physical and mechanical parameters of the model were shown in Tab. 1. 


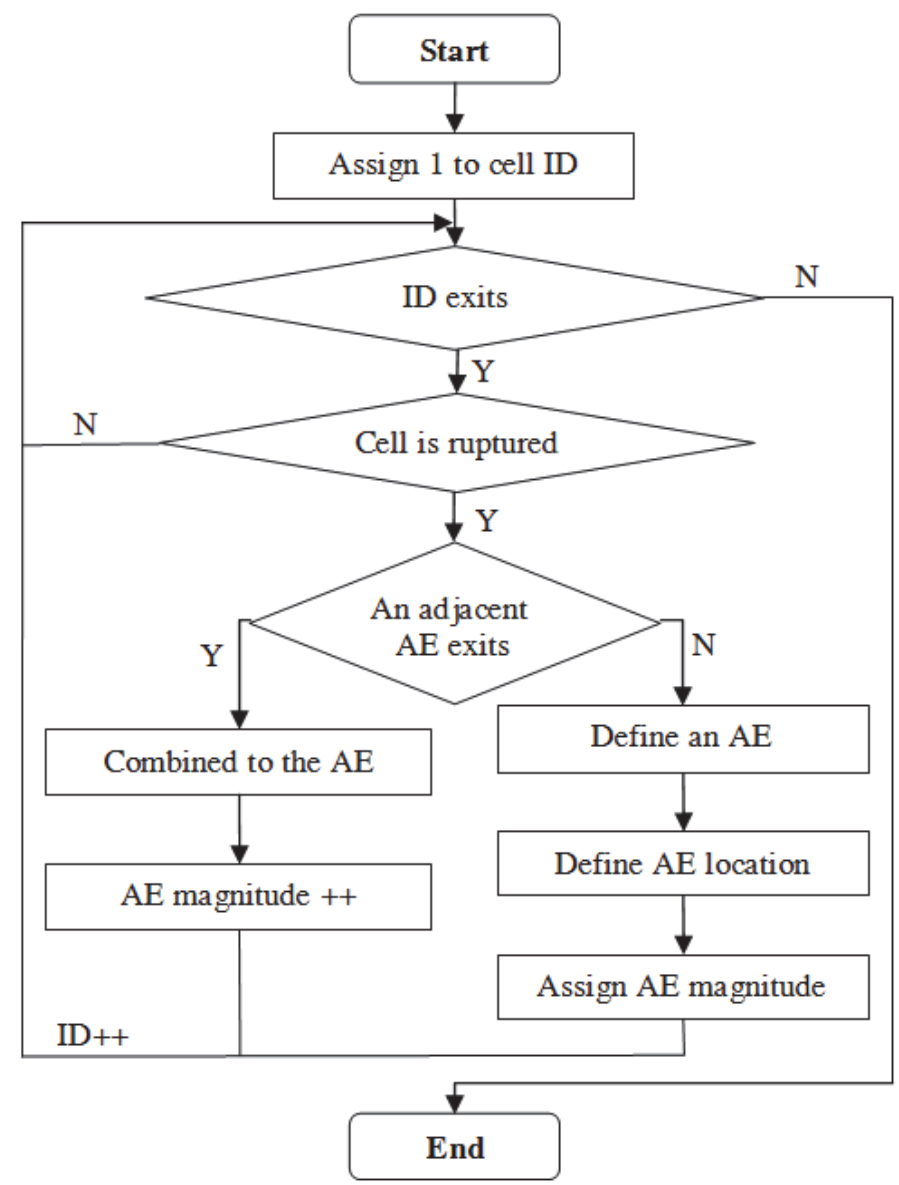

Figure 3: The flow chart of recording AE events.

\begin{tabular}{ccccccc}
\hline Name & $\begin{array}{c}\text { Density } \\
{\left[\mathrm{kg} / \mathrm{m}^{3}\right]}\end{array}$ & $\begin{array}{c}\text { Bulk modulus } \\
{[\mathrm{GPa}]}\end{array}$ & $\begin{array}{c}\text { Shear modulus } \\
{[\mathrm{GPa}]}\end{array}$ & $\begin{array}{c}\text { Cohesion } \\
{[\mathrm{MPa}]}\end{array}$ & $\begin{array}{c}\text { Friction } \\
\text { angle }\left[{ }^{\circ}\right]\end{array}$ & $\begin{array}{c}\text { Tension } \\
{[\mathrm{MPa}]}\end{array}$ \\
Main cells & 2650 & 15 & 11 & 2.8 & 45 & 0.60 \\
Defective cells & 2650 & 15 & 11 & 2.8 & 45 & 0.55 \\
Weak cells & 2650 & 15 & 11 & 2.8 & 45 & 0.14 \\
\hline
\end{tabular}

Table 1: Physical and mechanical parameters of the model.

\section{Loading and Boundary Conditions}

As shown in Fig. 5, the rock plate was hinged to the both ends with the fixed bearing in the vertical direction and the spring bearing with a stiffness $6.0 \times 10^{4} \mathrm{~N} / \mathrm{m}$ respectively in the horizontal direction. The concentrated loading was applied in a circular zone with a diameter of $10 \mathrm{~mm}$ in the center of the upper surface of the model. To avoid drastic disturbance of the calculating system, the compressive stress was increased linearly from 0 to a final stress of $12.0 \mathrm{MPa}$.

\section{RESULTS}

\section{AE in the Failure Process of the Rock Plate}

s shown in AE location maps (Fig. 6), the results showed the obvious distribution differences between the initial cracks and the ultimate cracks of the rock plate in the test. And the AE hits-time curve could be divided into four stages in the process of bearing load to instability of the rock plate under the concentrated loading condition (Fig. 7). 


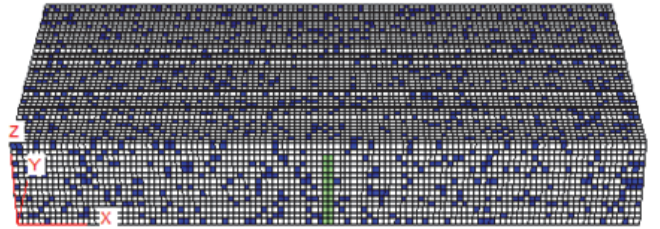

\section{Block Group}

defective cells

main cells

weak cells

Figure 4: The computational model and its grids.

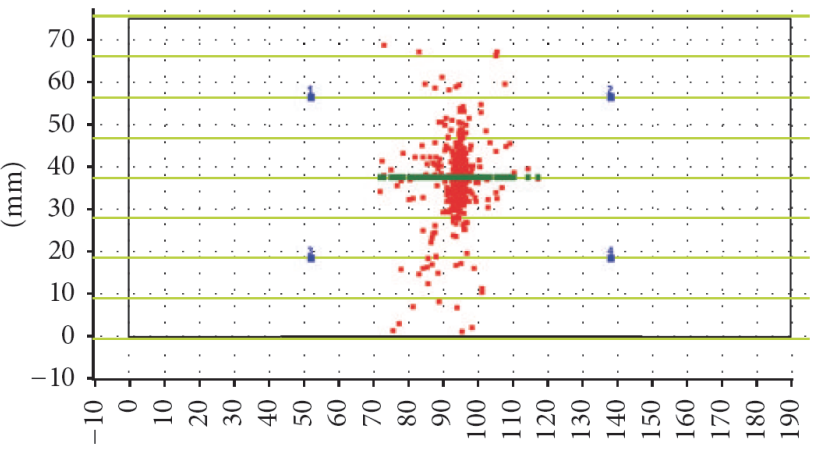

$(\mathrm{mm})$

(a) Initial stage.

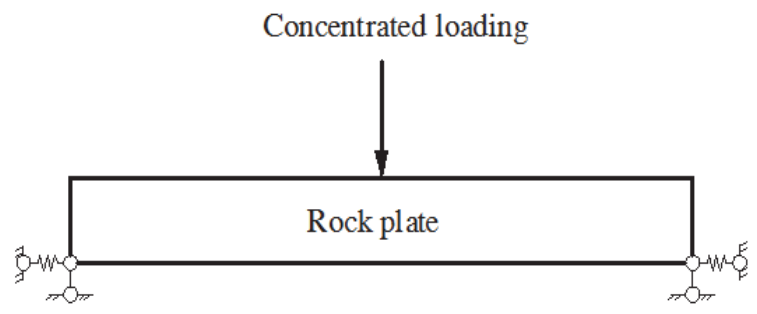

Figure 5: Loading and boundary conditions.

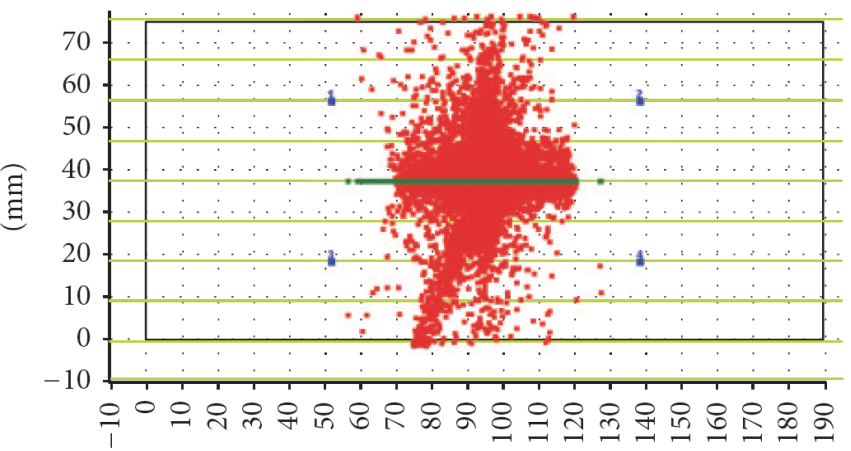

$(\mathrm{mm})$

(b) Ultimate stage.

Figure 6: AE locations on rock plate.

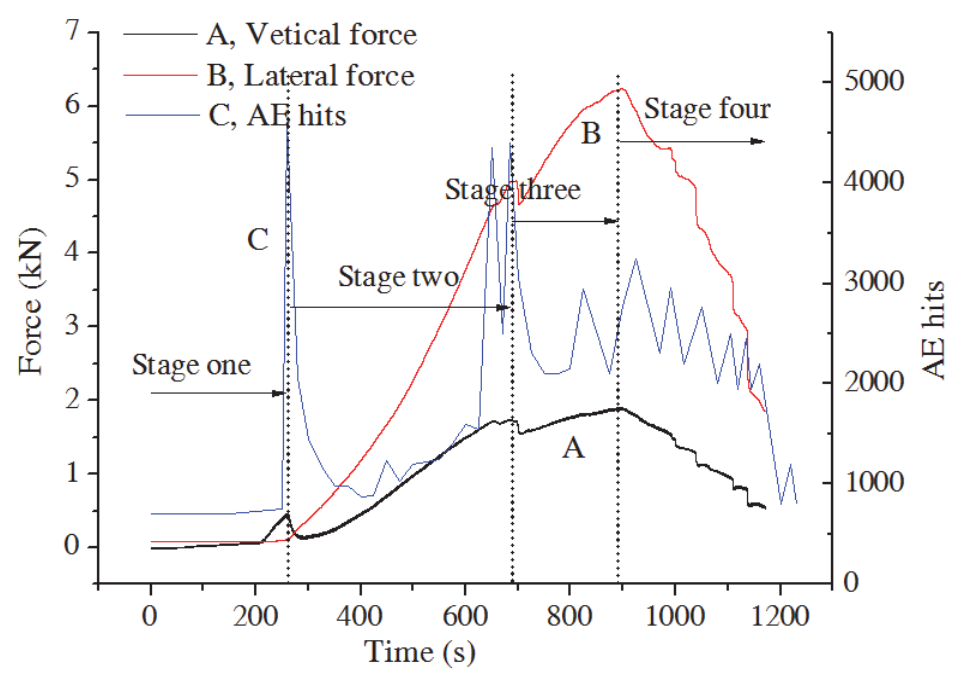

Figure 7: AE hits and force-displacement curves under the concentrated loading.

\section{AE Characteristics in Numerical Simulation Test}

The results were saved in each particular time interval to observe AE states of cells as shown in Fig. 8. The recording function was applied to record the AE amount (Fig. 9) and AE locations (Fig. 10). During the loading process, the stress in the rock plate transmitted in every step and the cell ruptured when the stress in a particular cell reached the shearing or the tension strength. The ruptured cells began in the center of the rock plate bottom, then extended along the center line of the rock plate resulting in a fracture in the middle, and finally formed a rock-arch structure. Meanwhile, the AE events mainly gathered on the hinged lines of the rock-arch structure in the rock plate.

From the above mentioned results, we can see that the numerical simulation showed nearly the same AE characteristics with those of the laboratory test. As shown in Fig. 9, the AE hits-step curve can be divided into four stages: 


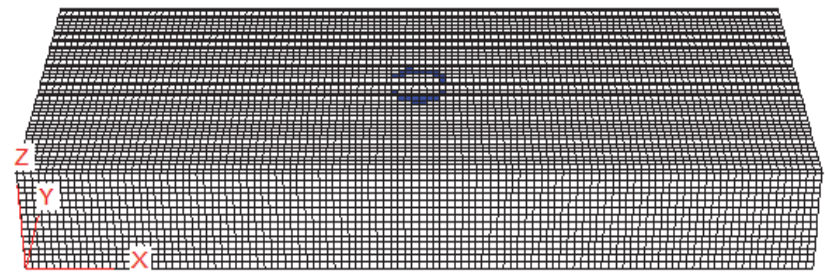

(a) Initial stage (3000 steps).

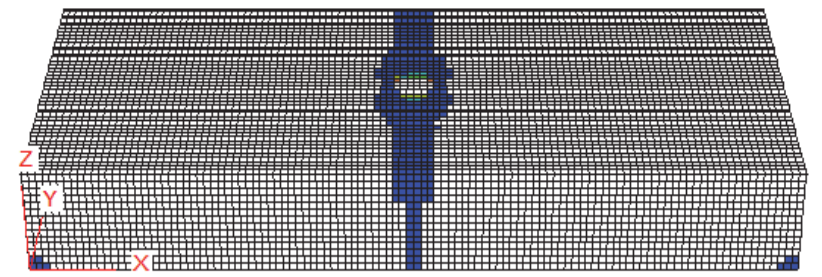

(b) Ultimate stage (12000 steps).

Figure 8: AE locations on the top of the rock plate.

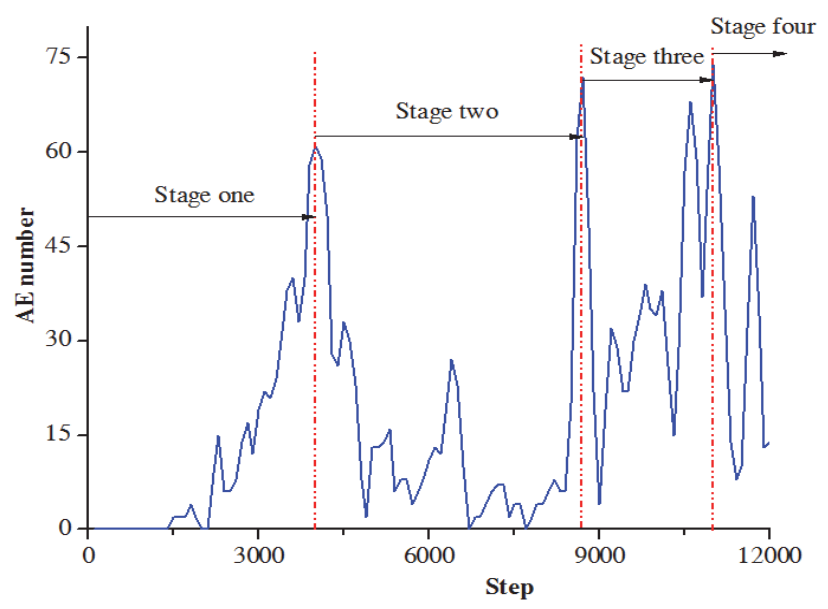

Figure 9: AE hits-step curve in the numerical simulation.

Stage 1 (stress adjusting stage): The stress has not yet reached the tensile strength of the sandstone sample in the early time, so a large number of AE events were avoided. And then an initial crack paralleling with the short sides formed in the center of the rock plate boring the largest tensile stress. The stresses transmitted in FLAC ${ }^{3 \mathrm{D}}$ by the neighboring nodes in the calculating process, redistributing in each step. For the stress in the rock plate increased gradually under the concentrated loading, the sample generated the displacements on its bottom of the both ends, which induced the horizontal constraining force. Few AE events had been recorded at first and then it increased sharply to the first peak. The AE events induced by the tensile rupture mainly gathered near the first crack.

Stage 2 (the brittle fracture stage): In this stage, the extended crack resulted in the rock plate fracturing into two halves and being formed a hinged rock-arch structure. Both the laboratory test and numerical simulation showed that the number of AE events decreased rapidly and stabilized in a low level. This indicated that the rock plate produced a brittle fracture induced by the extent of the first crack. Both the laboratory test and the simulation showed the same characteristics in the spatial distribution, namely AE events spread from the center to the ends with the extent of the initial crack (Fig. 10).

Stage 3 (rock-arch structure bearing loading): The hinged rock-arch structure boring the loading and the horizontal force continued to increase with the loading increasing. The AE characteristics in the laboratory test and the numerical simulation were nearly the same, namely the AE number performed a sharp increase to reach the second peak and then it reduced and stabilized. The AE spatial distribution focused on the hinge lines of the rock-arch structure, namely the center line and the ends of the rock plate (Figs. 8 and 10).

Stage 4 (instability and failure of the rock-arch structure): Once the concentrated load exceeded the bearing capacity of the rock-arch structure, it would lead to the instability and failure of the rock plate. The AE events reduced unsteadily and distributed in the middle and the ends of the rock plate both in the laboratory test and the numerical simulation (Figs. 8 and 10).

\section{DISCUSSION OF THE MAGNITUDES OF AE EVENTS}

A

s we can see that all these 156 large magnitude events revealed the similar spatial distribution to the AE events, and which were located on the main crack of the sample, namely the middle hinge of the rock-arch structure (Fig. 10). 


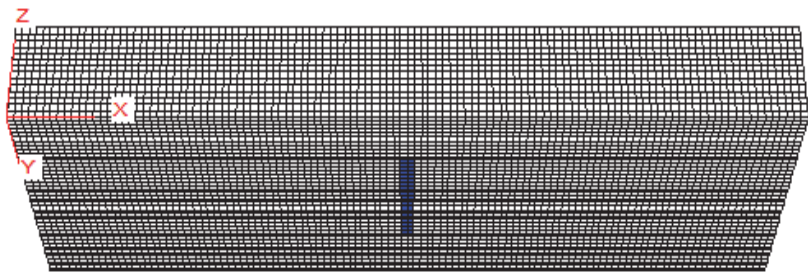

(a) Initial stage (3000 steps).

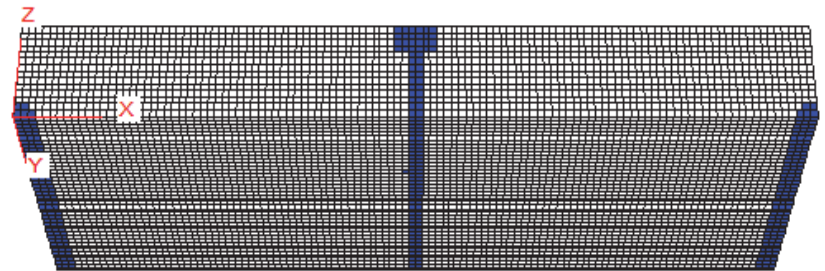

(b) Ultimate stage (12000 steps).

Figure 10: AE locations on the bottom of the rock plate.

There are all $1145 \mathrm{AE}$ events and the number of the ruptured cells corresponded to one AE event from 1 to 5 in the numerical simulation, which represented the different energy scale released in one AE event. In the fracture and instability process of the rock plate, the number of AE events reduced with the AE magnitude increasing. As shown in Fig. 11, we can obtain the negative exponential formula by fitting the curve by using Origin Software wherein $N$ indicating the number of AE with magnitudes greater than or equal to $m$ while $m$ indicating the AE magnitude.

In seismology, the earthquake with a larger magnitude is relatively rare, while some small magnitude earthquakes occur frequently. The relationship between the magnitude and frequency is generally described by a probability distribution, which is derived based on the statistics of the observed seismic activity. The most widely used relationship is the following one $[19,20]$ :

$$
N=10^{a-b m}
$$

where $N$ indicates the number of earthquakes with the magnitudes greater than or equal to $m$; $m$ indicates the magnitude; a and $\mathrm{b}$ are regional parameters. For example, Z.H. El-Isa, et al. compiled the seismicity data for all earthquakes with magnitudes $m \geq 4.5$ occurred globally from January, 1990 to December, 2012. The fitting result is presented in Fig. 12 [21]. The AE phenomena and tectonic earthquakes are both releasing energy processes induced by the slippage or breakage of rock sample or stratum, and having substantial connection in the failure mechanism. In addition, the similarity of distribution in frequency corroborates this law indirectly.

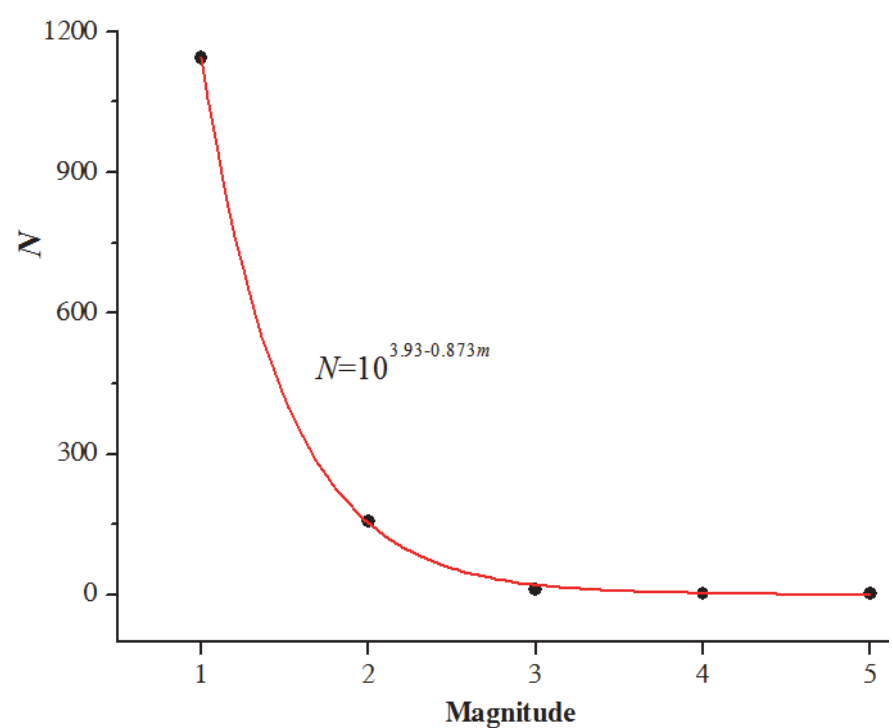

Figure 11: AE magnitude distribution curve.

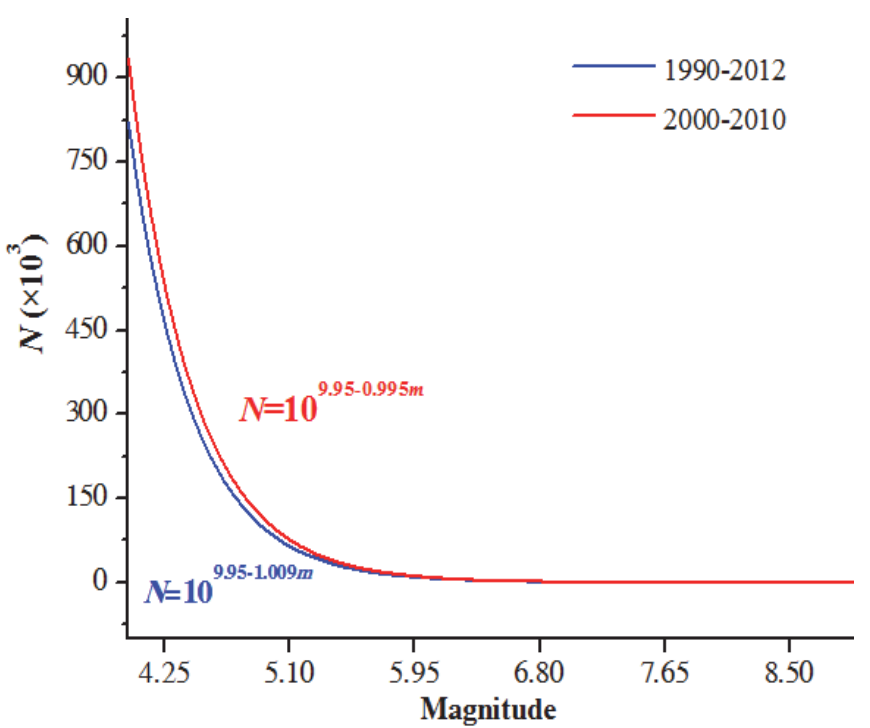

Figure 12: Magnitude frequency distribution of the seismicity.

\section{CONCLUSIONS}

$\mathrm{B}$ ased on the laboratory test and simulation results, the process of the fracture and instability for the rock plate could be divided into four stages: the stress adjusting stage, the brittle fracture stage, the rock-arch bearing load stage, and the rock-arch instability stage. The acoustic emission exhibited the different characteristics in each stage. 
By a self-programming recording function in FLAC $3 \mathrm{D}$, these AE events with large magnitudes were abstracted. We found that the similar temporal and spatial characteristics between the large magnitude AE events and the whole AE events, which reflected the feature of the instability process of the rock plate.

The AE distribution with the magnitude showed that the AE events reduced with the AE magnitudes followed a negative exponential function. This distribution was similar to the tectonic earthquakes, which reflected the intrinsic link between the AE events and the AE magnitudes.

\section{ACKNOWLEDGEMENTS}

his work was supported by the National Natural Science Foundation of China (51474188; 51474097; 51074140), the Natural Science Foundation of Hebei Province of China (E2014203012), the International Cooperation Project of Henan Science and Technology Department (162102410027), the Doctoral Fund of Henan Polytechnic University (B2015-67), and Program for Taihang Scholars. All these were gratefully acknowledged.

\section{REFERENCES}

[1] Li, S.L., Yin, X.G., Wang, Y.J., Tang, H.Y., Studies on acoustic emission characteristics of uniaxial compressive rock failure. Chinese Journal of Rock Mechanics and Engineering, 23 (15) (2004) 2499-2503.

[2] Fu, X.M., Experimental study on uniaxial compression deformation and acoustic emission property of typical rocks. Journal of Chengdu University of Technology, 32 (1) (2005) 17-21.

[3] Zhao, X.D., Tang, C.A., Li, Y.H., Yuan, R.F., Zhang, J.Y., Study on AE activity characteristics under uniaxial compression loading. Chinese Journal of Rock Mechanics and Engineering, $25\left(\mathrm{~S}_{2}\right)$ (2006) 3673-3678.

[4] Liu, J.P., Xu, S.D., Li, Y.H., Dong, L.B., Wei, J., Studies of AE time-space evolution characteristics during failure process of rock specimens with prefabricated holes. Chinese Journal of Rock Mechanics and Engineering, 31 (12) (2012) 2538-2547.

[5] Zhang, Y.B., Spectral character analysis of sandstone under saturation condition in rupture procedure, Rock and Soil Mechanics, 34 (6) (2013) 1574-1578.

[6] Jia, L.C., Chen, M., Zhang, W., Xu, T., Zhou, Y., Hou, B., Jin, Y., Experimental study and numerical modeling of brittle fracture of carbonate rock under uniaxial compression. Mechanics Research Communications, 50 (2013) 58-62. DOI: $10.1016 /$ j.mechrescom.2013.04.002.

[7] Huang, B.X., Liu, J.W., The effect of loading rate on the behavior of samples composed of coal and rock. International Journal of Rock Mechanics \& Mining Sciences, 61 (2013) 23-30. DOI: 10.1016/j.ijrmms.2013.02.002.

[8] Zhao, K., Zhu, Z.C., Zeng, P., Cheng, S.J., Experimental study on acoustic emission characteristics of phyllite specimens under uniaxial compression. Journal of Engineering Science and Technology Review, 8 (3) (2015) 53-60.

[9] Karakus, M., Perez, S., Acoustic emission analysis for rock-bit interactions in impregnated diamond core drilling. International Journal of Rock Mechanics \& Mining Sciences, 68 (2014) 36-43. DOI: 10.1016/j.ijrmms.2014.02.009.

[10] Aker, E., Kühn, D., Vavryèuk, V., Soldal, M., Oye, V., Experimental investigation of acoustic emissions and their moment tensors in rock during failure. International Journal of Rock Mechanics \& Mining Sciences, 70 (2014) 286295. DOI: 10.1016/j.ijrmms.2014.05.003.

[11] Frash, L.P., Gutierrez, M., Hampton, J., Hood, J., Laboratory simulation of binary and triple well EGS in large granite blocks using AE events for drilling guidance. Geothermics, 55 (2015) 1-15. DOI: 10.1016/j.geothermics.2015.01.002.

[12] Liu, N., Zhang, C.S., Chu, W.J., Wu, X.M., Microscopic characteristics analysis of brittle failure of deep buried marble. Chinese Journal of Rock Mechanics and Engineering, $31\left(\mathrm{~S}_{2}\right)(2012)$ 3557-3565.

[13] Ren, X.H., Wang, H.J., Zhang, J.X., Numerical study of AE and DRA methods in sandstone and granite in orthogonal loading directions. Water Science and Engineering, 5 (1) (2012) 93-104. DOI: $10.3882 /$ j.issn.1674-2370.2012.01.009.

[14] Wang, X.B., Numerical simulation of failure processes and acoustic emissions of rock specimens with different strengths, Journal of University of Science and Technology Beijing, 30 (8) (2008) 837-843.

[15] Han, T.C., Zhang, H.J., Numerical simulation of acoustic emission for defective rock. Chinese Journal of Rock Mechanics and Engineering, $33\left(\mathrm{~S}_{1}\right)$ (2014) 3198-3024. 
[16] Poerbandono, R., Suprijo, T., Modification of attenuation rate in range normalization of echo levels for obtaining frequency-dependent intensity data from 0.6 MHz and 1.0 MHz devices. Journal of Engineering and Technological Sciences, 45B (2) (2013) 140-152. DOI: 10.5614/j.eng.technol.sci.2013.45.2.3.

[17] Miljenko, K., Sinia, F., Marin, M., Principal component analysis in determining the best setup for acoustic measurements in sound control rooms. Tehnicki Vjesnik, 22 (5) (2015) 1327-1335. DOI: $10.17559 / \mathrm{TV}-20150519115944$.

[18] Garcia-Barruetabena, J., Cortes-Martinez, F., Isasa-Gabilondo, I., Study of the acoustic absorption properties of panels made from ground tire rubbers. DYNA, 89 (2) (2014) 236-242. DOI: 10.6036/5710.

[19] Yoder, M.R., Holliday, J.R., Turcotte, D.L., Rundle, J.B., A geometric frequency-magnitude scaling transition: Measuring $b=1.5$ for large earthquakes. Tectonophysics, 532-535 (2012) 167-174. DOI: 10.1016/j.tecto.2012.01.034.

[20] Yucemen, M.S., Akkaya, A.D., Robust estimation of magnitude-frequency relationship parameters. Structure Safety, 38 (2012) 32-39. DOI: 10.1016/j.strusafe.2012.02.002.

[21] El-Isa, Z.H., Eaton, D.W., Spatiotemporal variations in the b-value of earthquake magnitude-frequency distributions: Classification and causes. Tectonophysics, 615-616 (2014) 1-11. DOI: 10.1016/j.tecto.2013.12.001. 